\title{
A commentary on "Ten-year follow-up results of a randomized clinical trial comparing left thoracoabdominal and abdominal transhiatal approaches to total gastrectomy for adenocarcinoma of the oesophagogastric junction or gastric cardia"
}

\author{
Shinji Mine, Masayuki Watanabe \\ Department of Gastroenterological Surgery, Cancer Institute Hospital, 3-8-31, Ariake, Koto-ku, Tokyo, 135-8550, Japan \\ Correspondence to: Shinji Mine. Department of Gastroenterological Surgery, Cancer Institute Hospital, 3-8-31, Ariake, Koto-ku, Tokyo 135-8550, \\ Japan. Email: shinji.mine@jfcr.or.jp.
}

Received: 15 January 2016; Accepted: 21 January 2016; Published: 16 March 2016.

doi: $10.21037 / \operatorname{tgh} .2016 .03 .08$

View this article at: http://dx.doi.org/10.21037/tgh.2016.03.08

Kurokawa and other authors published 10-year outcomes of a Japanese randomized clinical trial comparing left thoracoabdominal approaches (LTA) with abdominal transhiatal approaches (TH) for adenocarcinoma of the esophagogastric junction (AEG) (JCOG9502) (1). That study demonstrated that LTA was not superior to TH regarding AEG patients' survival, but had a higher incidence of morbidity than TH (2). Moreover, the authors stratified patients into Siewert type II or type III and showed that LTA should be avoided especially for the latter.

This trial is one of only two prospective randomized trials comparing surgical approaches for AEG. The other is a Dutch study which compared transthoracic esophagectomy with transhiatal esophagectomy $(3,4)$. For Siewert type II patients, there were no survival differences between LTA and TH in the JCOG9502 study (1). These results are similar to those of the Dutch study which showed that survival of Siewert type II patients was not different whether a transthoracic or transhiatal approach was employed (4).

When the results of this study are interpreted in clinical practice, we have to be careful in three respects. First, this is a Japanese study from 15 years ago; second, eligible patients were limited to those with $\leq 3 \mathrm{~cm}$ of esophageal invasion; and third, the more recent surgical approach, minimally invasive surgery (MIS), needs to be considered.

In this study, patients were recruited from 1995 to 2003, so it began about 15 years ago. At that time, Japanese doctors had hardly ever seen patients with esophageal adenocarcinoma or long-segment Barrett's esophagus. It was considered that total gastrectomy with lower esophagectomy had been sufficient for most of our patients with AEG, and all patients in this study underwent total gastrectomy. However, in the intervening two decades, patients with esophageal adenocarcinoma or long-segment Barrett's esophagus have become relatively common even in Japan. This is probably because the numbers of obese people has increased and the incidence of Helicobacter pylori infection decreased in Japan. I speculate that the patients' characteristics have changed during these 20 years and tumor location has moved more to the oral side, as in patients in Western countries. Nowadays, we encounter AEG patients more frequently for whom esophagectomy rather than total gastrectomy is more appropriate.

In addition, eligible patients in this study were limited to those with $\leq 3 \mathrm{~cm}$ of esophageal invasion (defined as the length from the esophagogastric junction to the proximal end of the tumor). However, it is well-known that preoperative determination of the esophagogastric junction is very difficult, especially in a circumferential tumor. Even Siewert classification is reported not always to correspond with preoperative endoscopic diagnosis (5). Moreover, when the AEG tumor is located in the thorax and its esophageal invasion is $\leq 3 \mathrm{~cm}$, the necessity for middle or upper mediastinal lymphadenectomy is not clear.

Another confounder is MIS, which has become the standard treatment in the last two decades. Thoracoscopic esophagectomy or MIS transhiatal esophagectomy 
is now being performed routinely. In contrast, esophagojejunostomy after total gastrectomy with lower esophagectomy is considered to be more difficult under MIS. As a result, the frequency of total gastrectomy for AEG has declined in Western countries.

In conclusion, this study is a milestone in surgical strategy for AEG patients. It demonstrated that LTA should be avoided for AEG patients with $\leq 3 \mathrm{~cm}$ esophageal invasion, especially for Siewert type III. Further studies are necessary before the results of this investigation can be applied in clinical practice in this current era of MIS.

\section{Acknowledgements}

None.

\section{Footnote}

Provenance: This is a Guest Commentary commissioned by the Section Editor Dr. Rulin Miao (Department of Gastrointestinal Surgery, Peking University Cancer Hospital \& Institute, Beijing, China).

Conflicts of Interest: The authors have no conflicts of interest to declare.

doi: $10.21037 / \operatorname{tgh} .2016 .03 .08$

Cite this article as: Mine S, Watanabe M. A commentary on "Ten-year follow-up results of a randomized clinical trial comparing left thoracoabdominal and abdominal transhiatal approaches to total gastrectomy for adenocarcinoma of the oesophagogastric junction or gastric cardia". Transl Gastroenterol Hepatol 2016;1:12.

\section{References}

1. Kurokawa Y, Sasako M, Sano T, et al. Ten-year followup results of a randomized clinical trial comparing left thoracoabdominal and abdominal transhiatal approaches to total gastrectomy for adenocarcinoma of the oesophagogastric junction or gastric cardia. Br J Surg 2015;102:341-8.

2. Kurokawa Y, Sasako M, Sano T, et al. Functional outcomes after extended surgery for gastric cancer. Br J Surg 2011;98:239-45.

3. Hulscher JB, van Sandick JW, de Boer AG, et al. Extended transthoracic resection compared with limited transhiatal resection for adenocarcinoma of the esophagus. $\mathrm{N}$ Engl J Med 2002;347:1662-9.

4. Omloo JM, Lagarde SM, Hulscher JB, et al. Extended transthoracic resection compared with limited transhiatal resection for adenocarcinoma of the mid/distal esophagus: five-year survival of a randomized clinical trial. Ann Surg 2007;246:992-1000; discussion 1000-1.

5. Grotenhuis BA, Wijnhoven BP, Poley JW, et al. Preoperative assessment of tumor location and stationspecific lymph node status in patients with adenocarcinoma of the gastroesophageal junction. World J Surg 2013;37:147-55. 